Vítor Monteiro, Bruno Exposto, J. G. Pinto, Raul Almeida, João C. Ferreira, João L. Afonso

"On-Board Electric Vehicle Battery Charger with Enhanced V2H Operation Mode"

IEEE IECON Industrial Electronics Conference, pp.1636-1642, Dallas Texas USA, Oct. 2014.

http://ieeexplore.ieee.org/xpl/articleDetails.jsp?reload=true\&arnumber=7048722

ISBN: 978-1-4799-4033-2

ISSN: $1553-572 \mathrm{X}$

DOI 10.1109/IECON.2014.7048722

This material is posted here with permission of the IEEE. Such permission of the IEEE does not in any way imply IEEE endorsement of any of Group of Energy and Power Electronics, University of Minho, products or services. Internal or personal use of this material is permitted. However, permission to reprint/republish this material for advertising or promotional purposes or for creating new collective works for resale or redistribution must be obtained from the IEEE by writing to pubs-permissions@ieee.org. By choosing to view this document, you agree to all provisions of the copyright laws protecting it.

(C) 2014 IEEE 


\title{
On-Board Electric Vehicle Battery Charger with Enhanced V2H Operation Mode
}

\author{
Vítor Monteiro $^{1}$, Bruno Exposto ${ }^{1}$, J. G. Pinto ${ }^{1}$, Raul Almeida ${ }^{1}$, João C. Ferreira ${ }^{1}$, \\ Andrés A. Nogueiras Meléndez ${ }^{2}$, João L. Afonso ${ }^{1}$ \\ ${ }^{1}$ ALGORITMI Research Centre - University of Minho, Guimarães - Portugal \\ ${ }^{2}$ Departamento de Tecnología Electrónica - University of Vigo, Vigo - Spain \\ ${ }^{1}$ \{vitor.monteiro | bruno.exposto | gabriel.pinto | raul.almeida | joao.ferreira | joao.l.afonso\}@aalgoritmi.uminho.pt \\ 2aaugusto@uvigo.es
}

\begin{abstract}
This paper proposes an on-board Electric Vehicle (EV) battery charger with enhanced Vehicle-to-Home (V2H) operation mode. For such purpose was adapted an on-board bidirectional battery charger prototype to allow the Grid-to-Vehicle (G2V), Vehicle-to-Grid (V2G) and V2H operation modes. Along the paper are presented the hardware topology and the control algorithms of this battery charger. The idea underlying to this paper is the operation of the on-board bidirectional battery charger as an energy backup system when occurs a power outages. For detecting the power outage were compared two strategies, one based on the half-cycle rms calculation of the power grid voltage, and another in the determination of the rms value based in a Kalman filter. The experimental results were obtained considering the on-board EV battery charger under the $\mathbf{G} 2 \mathrm{~V}, \mathrm{~V} 2 \mathrm{G}$, and $\mathrm{V} 2 \mathrm{H}$ operation modes. The results show that the power outage detection is faster using a Kalman filter, up to $90 \%$ than the other strategy. This also enables a faster transition between operation modes when a power outage occurs.
\end{abstract}

Keywords-Backup Power Supply, Bidirectional Battery Charger, Electric Vehicles, Kalman Filter, Enhanced Vehicle-to-Home (V2H)

\section{INTRODUCTION}

Electric Vehicles (EVs) are being introduced as a new promising transport in different countries around the world [13]. As example, for the US it is foreseeable that EVs will represent $64 \%$ of the light vehicles sales in 2030 [4]. As consequence of this new paradigm, new challenges and opportunities will arise. The main challenge is related with the regulation of the battery charging process from the power grid [1], [5]. This represents a challenge because will be required a significant amount of energy during the charging process and power quality problems cannot be neglected in such scenario [6-8]. On the other hand, the main opportunity that must be addressed is related with the capacity of these vehicles to store a significant amount of energy. Thereby, besides the battery charging process, identified as Grid-to-Vehicle (G2V) [9], the EVs can also be used to produce reactive power [10] and to deliver part of energy stored in the batteries back to the power grid. This process is identified as Vehicle-to-Grid (V2G) [1114]. These challenges and opportunities are more relevant considering the advances in smart grids and micro-grids [15], where these vehicles will be a key technology [16], [17]. In this scenario, also mobile information systems for EVs will be an important field to the electric mobility development [18].
This paper proposes an opportunity to the EVs operation that is associated with the Vehicle-to-Home (V2H) paradigm [19]. This opportunity consists in use the EVs as a home backup power supply. Therefore, is proposed an enhanced $\mathrm{V} 2 \mathrm{H}$ operation mode. The operation of the EVs as voltage source was already proposed by NISSAN through the "LEAF-to-Home" system. This system uses a dedicated "EV Power Station" to supply home loads [20]. This type of opportunity for smart homes will be a key technology for the expansion of electric mobility sector in smart grids [21], [22]. According to NISSAN, this initiative is a contribution to a zero-emissions society. The main drawback of the "LEAF-to-Home" is that it can only be used in the place where the equipment is installed. In order to avoid this drawback, in [23] is presented an on-board bidirectional battery charger capable to operate as $\mathrm{G} 2 \mathrm{~V}, \mathrm{~V} 2 \mathrm{G}$ and $\mathrm{V} 2 \mathrm{H}$ in the place where the $\mathrm{EV}$ is parked. As presented, through the operation as $\mathrm{V} 2 \mathrm{H}$, the EV can provide energy to any load connected to the EV in island mode. However, it has not the capability to operate as backup power supply. This paper joins the main benefits of aforementioned systems, i.e., the EV can be used as backup power supply at home and supply loads in isolated mode. This opportunity is more relevant taking into account that private vehicles are parked at home between 9 p.m. and 6 a.m. [24].

The most common backup power supply is the Uninterruptible Power Supply (UPS), which can be on-line or off-line [25]. Despite the benefits of the on-line UPS in protect the loads continuously, in most of the situations, the off-line UPS is suitable to protect the loads during power outages. Therefore, this paper proposes the use of an on-board EV battery charger as backup power supply operating like an

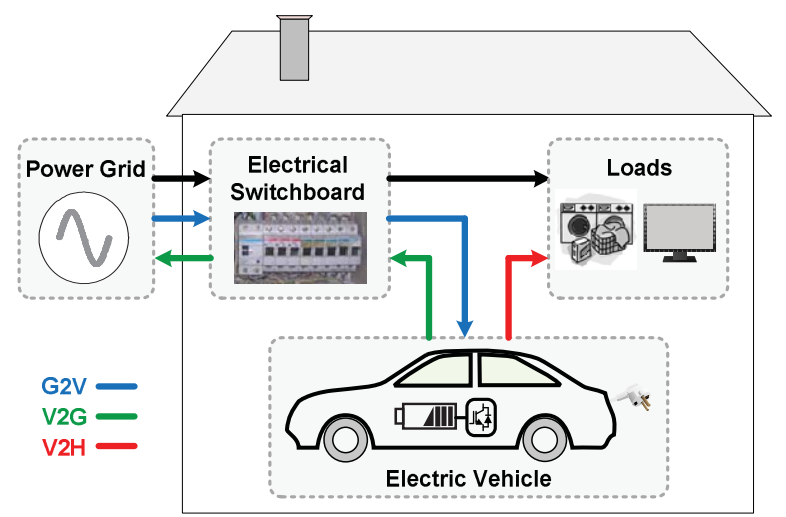

Fig. 1. Operation of an Electric Vehicle as backup power supply. 


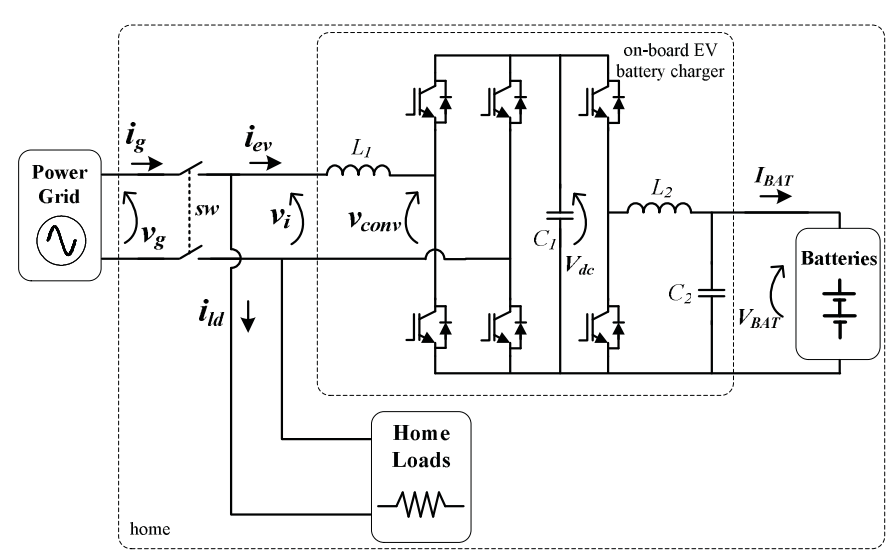

Fig. 2. Topology of the battery charger and the setup that was used to obtain the experimental results presented in the paper.

off-line UPS. The EV on-board battery charger are capable to perform a smooth transition between operation modes when a voltage sag or a power outage is detected. Fig. 1 shows the use of EVs as backup power supply.

\section{ON-BOARD EV BATTERY CHARGER PROTOTYPE}

Aiming to assess the operation of EVs as backup power supply it was adapted a bidirectional EV battery charger prototype to operate in accordance with the proposed enhanced V2H operation mode. The topology of this battery charger and the setup that was used to obtain the experimental results is presented in Fig. 2.

The battery charger that was used is divided in two power stages: one ac-dc front-end power converter; and one dc-dc non-isolated power converter. During the operation as G2V the ac-dc converter operates as active rectifier with sinusoidal current and unitary power factor, and the dc-dc adjusts the current and voltage to charge the batteries. In the V2G the ac-dc converter operates as inverter with sinusoidal current, and the dc-dc converter discharge the batteries with constant current. During the V2H mode, the ac-dc converter operates as controlled voltage source and the dc-dc converter is used to maintain the dc-link regulated. In order to synchronize the ac-dc converter with the power grid fundamental voltage was used a single-phase Phase-Locked Loop (PLL) [26]. From this algorithm is obtained a sine-wave signal pll that corresponds to the fundamental component of the power grid voltage. This signal is used to obtain the current reference for the G2V and $\mathrm{V} 2 \mathrm{G}$ operation modes. It can also be used to obtain the voltage reference in the $\mathrm{V} 2 \mathrm{H}$ operation mode. Therefore, PLL is the first algorithm implement in the control.

\section{A. Grid-to-Vehicle (G2V) and Vehicle-to-Grid (V2G)}

The control of the ac-dc and dc-dc converters is similar during the $\mathrm{G} 2 \mathrm{~V}$ and $\mathrm{V} 2 \mathrm{G}$ operation modes. In both of the modes, the dc-link is regulated by the ac-dc converter through a Proportional Integral (PI) controller. Also in both operation modes the current reference to the ac-dc converter is function of the power to charge $(\mathrm{G} 2 \mathrm{~V})$ or discharge (V2G) the batteries. The digital current reference in discrete time, at each instant $k$, is expressed as:

$$
i_{e v}{ }^{*}[\mathrm{k}]=\frac{P_{D C}{ }^{*}[k]+I_{B A T}[k] V_{B A T}[k]}{V_{g}[k]^{2}} \operatorname{pll}[k],
$$

where, $P_{D C}{ }^{*}$ is the reference obtained from the PI to regulate the dc-link, $V_{g}$ is the rms value of the power grid voltage, $p l l$ is the output of the PLL, and $I_{B A T}$ and $V_{B A T}$ are the current and voltage in the batteries, respectively. During the G2V operation mode the current $I_{B A T}$ and the voltage $V_{B A T}$ are positive, which results in a positive current reference. On the other side, during the $\mathrm{V} 2 \mathrm{G}$ operation mode the current $I_{B A T}$ is negative and the voltage $V_{B A T}$ remains positive, which results in a current reference in phase opposition with the power grid voltage.

In order to the ac-dc converter produce a voltage that results in the desired current $\left(i_{e v}{ }^{*}\right)$ was used a predictive current control. Taking into account that the ac-dc converter has a full-bridge structure, the reference that is compared with the $20 \mathrm{kHz}$ triangular carrier is expressed as:

$$
\begin{gathered}
v_{\text {conv }}[k]=v_{g}[k]-\frac{L_{1}}{T}\left(2 i_{e v}{ }^{*}[k]-i_{e v}{ }^{*}[k-1]\right. \\
\left.-i_{e v}[k]-i_{\text {ev_error }}[k-1]\right),
\end{gathered}
$$

where, $k$ denotes the actual sampling and $k-1$ the previous sampling. In this current control was used a unipolar PWM strategy. To mitigate the dead-time effects in the produced voltage was used a strategy that consists in add a constant value to the voltage reference $\left(v_{\text {conv }}[k]\right)$ during the positive semi-cycle, and subtract the same value during the negative semi-cycle. This value is calculated in function of the carrier amplitude and the delay introduced by the dead-time. To charge the batteries (G2V operation mode) in accordance with the batteries manufacture recommendations, the dc-dc converter requires two control strategies. The first consist in charge the batteries with constant current according to (3). The second consist in charge the batteries with constant voltage according to (4).

$$
\begin{gathered}
\delta_{\text {buck }}{ }^{*}[k]=V_{B A T}[k]-\frac{L_{2}}{T}\left(I_{B A T}{ }^{*}[k]-I_{B A T}[k]\right) . \\
\delta_{\text {buck }}{ }^{*}[k]=\frac{V_{B A T}{ }^{*}[k]}{V_{d c}[k]} .
\end{gathered}
$$

In order to discharge the batteries (V2G operation mode) with constant current is required a single control strategy. In this case the dc-link voltage is regulated by the ac-dc converter and is injected a current with variable amplitude (that is function of the batteries discharging current) in the power grid. In order to maintain the battery discharging current constant, the duty-cycle for the dc-dc converter is expressed by:

$$
\delta_{\text {boost }}{ }^{*}[k]=1-\frac{V_{B A T}[k]}{V_{d c}[k]+\frac{L_{2}}{T}\left(I_{B A T}{ }^{*}[k]-I_{B A T}[k]\right)} \text {. }
$$

\section{B. Vehicle-to-Home ( $\mathrm{V} 2 \mathrm{H})$}

In the $\mathrm{V} 2 \mathrm{H}$ operation mode the ac-dc converter is used to produce a voltage. The duty-cycle $\left(\delta_{a c-d c}\right)$ at each instant $k$ is expressed as: 


$$
\delta_{a c-d c}{ }^{*}[k]=\frac{v_{i}^{*}[k]}{V_{d c}[k]} .
$$

Also in this operation mode was used the aforementioned strategy to mitigate the effect of the dead-time in the produced voltage. In this mode the dc-dc converter is used to regulate the dc-link voltage, where the duty-cycle for the dc-dc converter is expressed by:

$$
\delta_{\text {boost }}{ }^{*}[k]=1-\frac{v_{B A T}[k]}{V_{d c}{ }^{*}[k]} .
$$

\section{Algorithms to Detect Power Outages}

In order to detect power outages, several algorithms can be implemented. Nevertheless, in the scope of this paper were analyzed and obtained experimental results with two algorithms. The first is based on the traditional calculation of the rms value and the second is based on the determination of the rms value using a Kalman filter. For both modes it was defined that occurs a voltage sag when the rms value is below $85 \%$ of its nominal value (standard EN 50160). These two control algorithms are described in detail. In the scope of this paper was assumed that when is detected a power outage the switch $S W$, represented in Fig. 2, is open and the home is disconnected from the power grid. When the voltage is restored the switch $S W$ is closed, however, only after a delay necessary to the complete synchronization of the PLL with the power grid voltage. Both situations are illustrated in Fig. 3.

\section{A. Traditional RMS Value Calculation}

A simple algorithm to detect voltage sags is based in the traditional calculation of the rms value. This method consists in calculate the rms value during one cycle of the power grid voltage and detect when it falls beyond a predefined threshold. The rms value is calculated according to:

$$
\mathrm{V}_{G(R M S)}(\mathrm{t})=\sqrt{\frac{1}{T} \int_{0}^{T} v_{g}^{2}(t) d t},
$$

and the digital implementation is:

$$
\mathrm{V}_{G(R M S)}[k]=\sqrt{\frac{1}{N} \sum_{k=1}^{k=N} v_{g}^{2}[k]},
$$

where, $N$ is the number of samples used in each cycle of the power grid voltage. Aiming to speed up the detection of changes in the rms value, it can be calculated using only half-cycle of the power grid voltage and using a sliding average across the square values of the power grid instantaneous values. The sliding sum used in the sliding average is calculated using:

$$
\operatorname{sum}[k]=\operatorname{sum}[k-1]-v_{g}{ }^{2}[k-N]+v_{g}{ }^{2}[k],
$$

and the rms value of the power grid voltage (half-cycle) is calculated using:
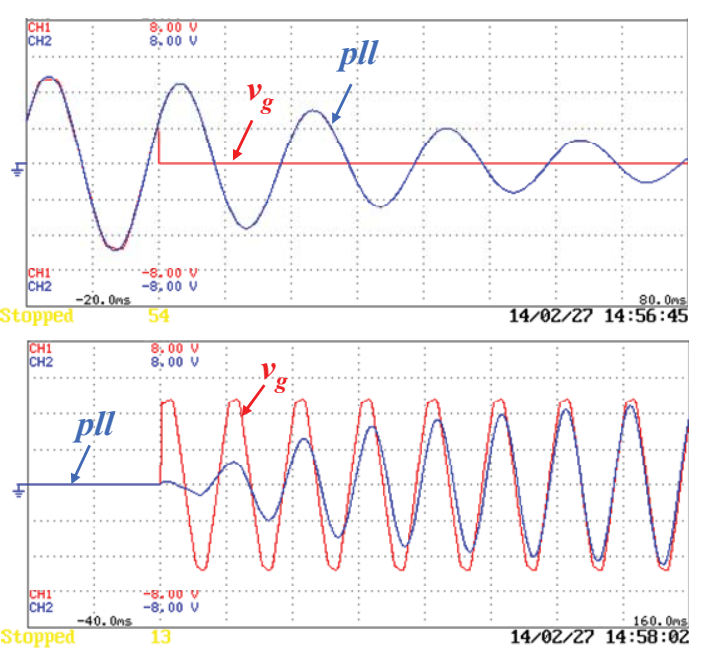

Fig. 3. Experimental results: Synchronization of the PLL with the power grid voltage before and after a power outage.

$$
\mathrm{V}_{G(R M S)}[k]=\sqrt{2 \frac{\operatorname{sum}[k]}{N}} .
$$

Fig. 4 shows the power grid voltage $\left(v_{g}\right)$, the output voltage of the ac-dc converter $\left(v_{i}\right)$, and the rms value $\left(V_{G(R M S)}\right)$, using this method and the limit of $85 \%$ of the rms nominal value $(230 \mathrm{~V})$. As shown, the power outage occurs a little after the beginning of the negative semi-cycle, and were required $3.3 \mathrm{~ms}$ to detect the power outage.

\section{B. RMS Value Estimation Based on Kalman Filter}

The algorithm for estimating the rms values using the Kalman filter is more complex than the traditional method presented before, however in most of the situations is faster to detect variations in the rms value. The Kalman filter used in this paper is based in the estimation of the instantaneous amplitude of the fundamental component of the power grid voltage and its quadrature signal, denoted as $s[k]$ and $q[k]$, respectively. The Kalman filter is based in two distinct set of equations: Prediction and Correction [27]. Assuming that there are only Additive White Gaussian Noise (AWGN) in the measured signal, it is possible establish the following estimation state model:

$$
\hat{x}[k]=\mathrm{A} \hat{x}[\mathrm{k}-1],
$$

where, $\hat{x}[k]$ is the estimation state model that comprises the in-phase and quadrature signals, where $x[k]$ is defined as:

$$
x[k]=\left[\begin{array}{l}
\mathrm{s}[\mathrm{k}] \\
q[k]
\end{array}\right]=\left[\begin{array}{c}
V_{g} \sin (\omega k T) \\
V_{g} \cos (\omega k T)
\end{array}\right],
$$

and $A$ is the state transition matrix defined by:

$$
A=\left(\begin{array}{cc}
\cos (\omega T) & \sin (\omega T) \\
-\sin (\omega T) & \cos (\omega T)
\end{array}\right)
$$

where, $\omega$ is the angular frequency of the power grid voltage and $T$ is the sampling period. The estimation of the process covariance is defined as:

$$
\hat{P}[k]=A P[k-1] A^{T}+Q,
$$




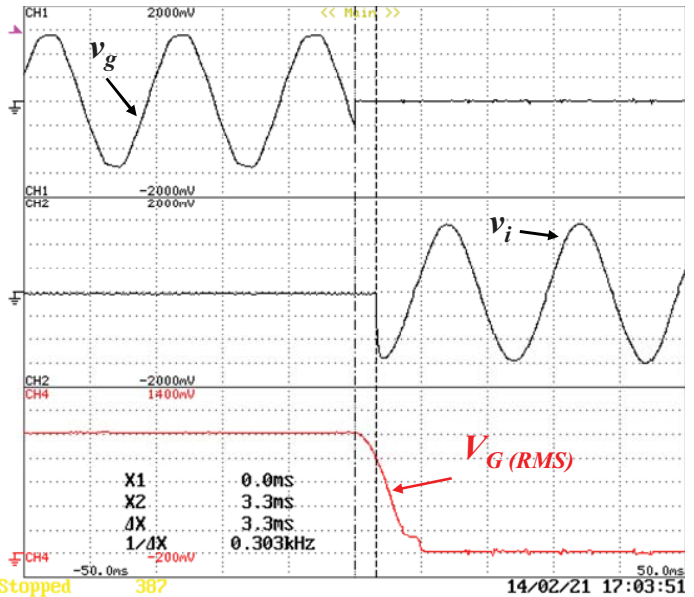

Fig. 4. Experimental results: Power grid voltage rms value estimation using a traditional method.

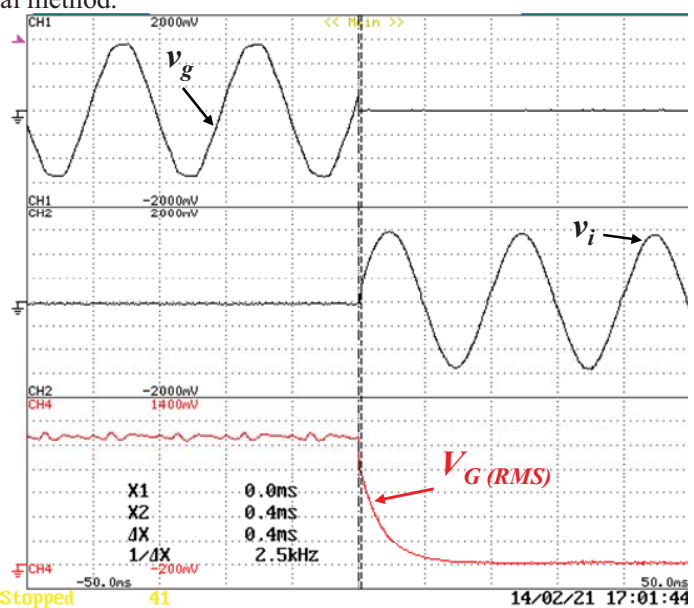

Fig. 5. Experimental results: Power grid voltage rms value calculation using a Kalman filter

where, $\mathrm{Q}$ is the covariance matrix. Equations 10 and 13 are related with the set of Prediction equations. In the set of Correction equations the first step is determine the optimal Kalman gains, which improves the estimation at each sampling frequency. The optimal Kalman gain matrix is described by:

$$
k[k]=\hat{P}[k] H^{T}\left(H \hat{P}[k] H^{T}+R\right)^{-1},
$$

where, $\hat{P}[k]$ is the estimation of the process covariance, $\mathrm{R}$ is represented by a scalar, and $H$ is defined as:

$$
H=\left[\begin{array}{ll}
1 & 0
\end{array}\right] \text {. }
$$

With the information obtained from the equation above the state estimation can be updated by:

$$
\hat{x}[k]=\hat{x}[k-1]+K\left(v_{i}-H \hat{x}[k-1]\right),
$$

and the covariance can be updated by:

$$
P[k]=(I-K H) \hat{P}[k] .
$$

The estimation of the rms value of the power grid voltage is given by:

$$
{\widehat{v_{g}}}_{R M S}[k]=\sqrt{\frac{\hat{s}[k]^{2}+\hat{q}[k]^{2}}{2}} .
$$

In this method, after estimate the rms value of the power grid voltage, when is identified that this value is below $85 \%$ of its nominal value, it is assumed a power outage and the EV must operate in V2H. Fig. 5 shows the power grid voltage $\left(v_{g}\right)$, the output voltage of the ac-dc converter $\left(v_{i}\right)$, and the rms value $\left(V_{G(R M S)}\right)$. In this situation, the power outage occurs a little after the beginning of the positive semi cycle, and was required $0.4 \mathrm{~ms}$ to detect the power outage. It must be referred that, although the detection moments are different, the Kalman filter method is faster than the traditional method.

\section{BATtERY CHARGER OPERATION MODES}

The battery charger prototype was submitted to a set of operation tests, mainly focusing the $\mathrm{V} 2 \mathrm{H}$ operation mode as a backup power supply. These tests were performed with the battery charger connected to the power grid at $115 \mathrm{~V}$. The dc-link voltage was regulated to $200 \mathrm{~V}$, and was used a set of 12 sealed 12 V 33 Ah Absorbed Glass Mat (AGM) batteries connected in series in order to perform $144 \mathrm{~V}$. To simulate the home loads were used resistances with the total value of $52 \Omega$. The aforementioned digital control algorithms were implemented in a DSP TMS320F28335 using a sampling frequency of $40 \mathrm{kHz}$. Fig. 6 shows the laboratory workbench used to validate the proposed $\mathrm{V} 2 \mathrm{H}$ operation mode and to obtain the experimental results, which were registered with a Yokogawa DL708E digital oscilloscope.

\section{A. Grid-to-Vehicle and Vehicle-to-Grid}

As aforementioned, during the $\mathrm{G} 2 \mathrm{~V}$ operation mode the energy flows from the power grid to the batteries and in the $\mathrm{V} 2 \mathrm{G}$ in the opposite way. In both operation modes, in the ac side, the current is sinusoidal. Fig. 7 shows the power grid voltage and the EV battery charger current for the G2V (Fig. 7 (a)) and V2G (Fig. 7 (b)) operation modes.

\section{B. Vehicle-to-Home}

During the $\mathrm{V} 2 \mathrm{H}$ operation mode the power flows from the batteries to the home loads. Besides the V2H operation mode, in which the EV battery charger is used as backup power supply, it can also be used to provide energy to any load connected to the EV in an island mode in the place where the $\mathrm{EV}$ is parked.

\section{Enhanced Vehicle-to-Home}




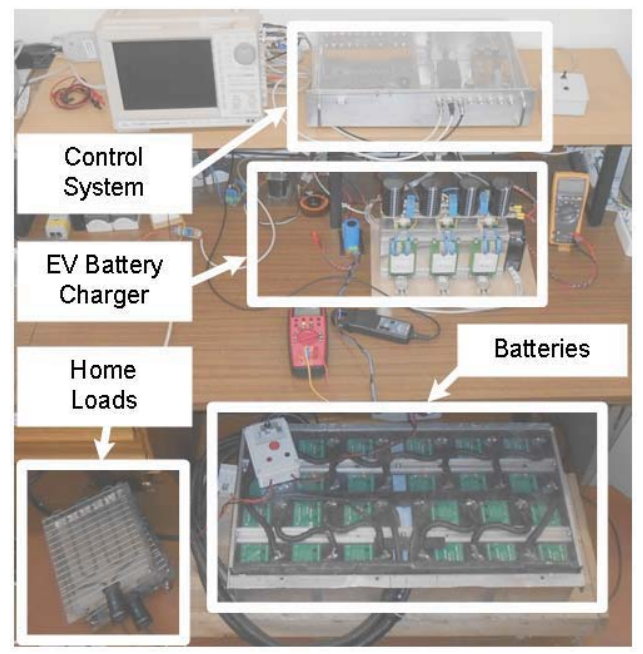

Fig. 6. Laboratory setup used to obtain the experimental results.
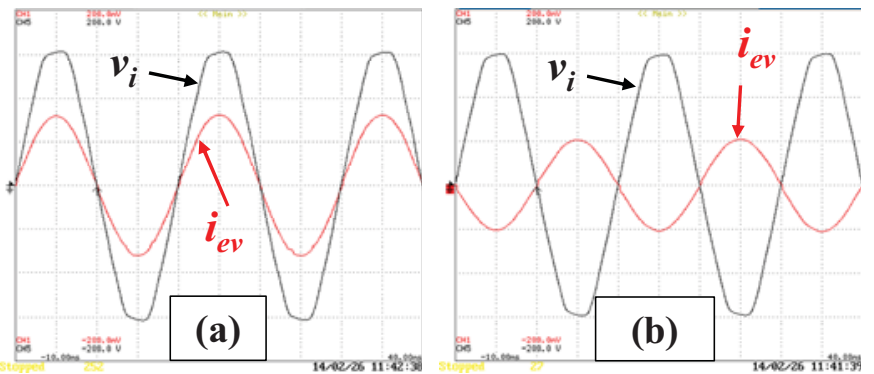

Fig. 7. Power grid voltage (50 V/div) and current $(5 \mathrm{~A} / \mathrm{div})$ in the battery charger: (a) During G2V operation mode; (b) During V2G operation mode.

During the enhanced V2H operation mode as backup power supply, the power flows from the batteries to the home loads. In this operation mode the ac-dc converter produces a sine-wave voltage and the current waveform is determined by the loads, and the dc-link voltage is regulated by the dc-dc converter. Considering that this operation mode can be triggered when the EV is only plugged in the home, or when it is plugged and in charge, this item is separated in these two distinct cases.

\section{1) Electric Vehicle Plugged but not in Charge}

In the enhanced $\mathrm{V} 2 \mathrm{H}$ operation mode were obtained experimental results with the traditional rms voltage calculation and using a Kalman filter. Fig. 8 (a) shows the voltage in the loads and the current in the battery charger using the traditional rms voltage calculation. As shown, to detect when the rms value decreases above $85 \%$ of its nominal value were required $3.8 \mathrm{~ms}$. On the other hand, Fig. 8 (b) shows the voltage in the loads and the current in the battery charger when is used the Kalman filter to detect the power outage. In this case, to detect when the rms values decreases above $85 \%$ of its nominal value were required only $0.3 \mathrm{~ms}$.

\section{2) Electric Vehicle Plugged and in Charge}

Also in the enhanced V2H operation mode were obtained experimental results, when the EV is charging, with the traditional RMS voltage calculation and using a Kalman filter to estimate the rms value. Fig. 9 shows the voltage in the loads and the current in the battery charger using the traditional rms

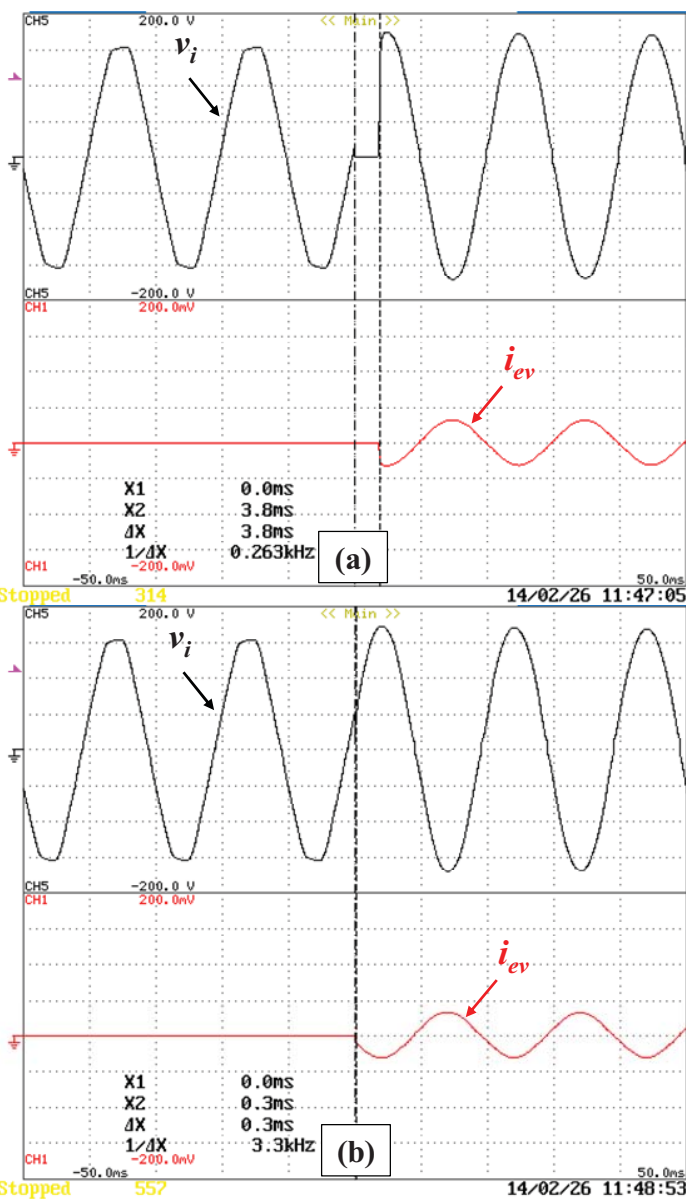

Fig. 8. Voltage $(50 \mathrm{~V} /$ div) in the load and current $(5 \mathrm{~A} / \operatorname{div} \mathrm{V})$ in the battery charger when the EV is plugged in but not in charge, when a power outage occurs: (a) Using a traditional RMS value calculation; (b) Using a Kalman filter do estimate the rms value.

voltage calculation and a Kalman filter, respectively. As shown, to detect when the rms values decreases above $85 \%$ of its nominal value were required $5.4 \mathrm{~ms}$ and $0.3 \mathrm{~ms}$, respectively. As shown during the battery charging process the current is in phase with the voltage, and after the power outage detection is in phase opposition.

\section{CONCLUSIONS}

This paper presents a study conducted in order to assess the utilization of an on-board Electric Vehicle (EV) battery charger operating as a backup power supply. The hardware topology and the control algorithms of the developed bidirectional battery charger prototype are described along the paper. In the scope of this paper it was defined that a power outage occurs when the rms value of the power grid voltage is $85 \%$ of its nominal value. To determine the rms value were compared two strategies: one based on the traditional rms calculation of half-cycle of the power grid voltage, and another based on a Kalman filter. The experimental results obtained show that using a Kalman filter the rms value detection is faster (typically $90 \%$ ) than with the traditional method. The operation of the battery charger was demonstrated through experimental results in Grid-to-Vehicle (G2V), Vehicle-to-Grid (V2G), and enhanced Vehicle-to-Home (V2H) operation modes. For the transition to the $\mathrm{V} 2 \mathrm{H}$ operation mode two distinct cases were 

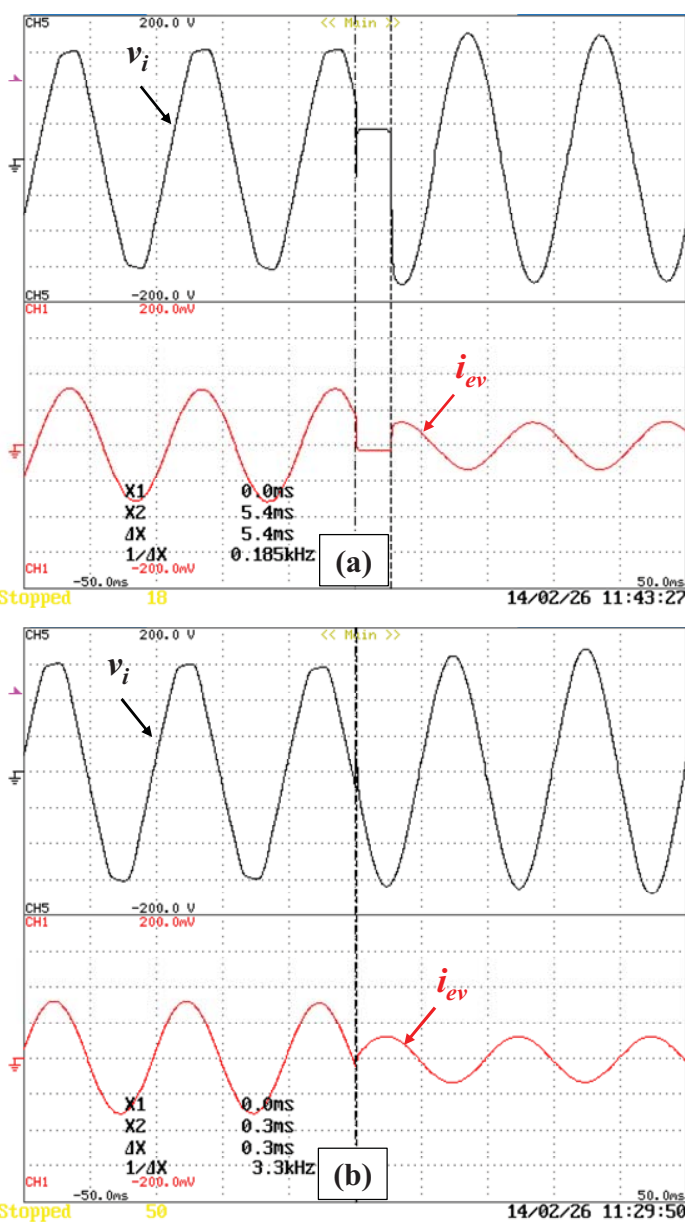

Fig. 9. Voltage $(50 \mathrm{~V} / \mathrm{div})$ in the load and current $(5 \mathrm{~A} / \mathrm{div})$ in the battery charger when the EV is plugged in and in charge, when a power outage occurs: (a) Using a traditional RMS value calculation; (b) Using a Kalman filter to estimate the rms value.

considered: when the EV was only plugged in to the home, and when the EV was plugged in and in charge (operating in $\mathrm{G} 2 \mathrm{~V}$ mode).

\section{ACKNOWLEDGMENT}

This work has been supported by FCT - Fundac $\square$ ão para a Cie $\square$ ncia e Tecnologia within the Project Scope: Pest OE/EEI/UI0319/2014. Mr. Vítor Monteiro was supported by the doctoral scholarship SFRH/BD/80155/2011 granted by the FCT agency.

\section{REFERENCES}

[1] Kevin J. Dyke, Nigel Schofield, Mike Barnes, "The Impact of Transport Electrification on Electrical Networks," IEEE Trans. Ind. Electron., vol.57, no.12, pp.3917-3926, Dec. 2010.

[2] G. Joos, M. R. Dubois, "Integration of PHEVs and EVs Experience from Canada," IEEE PES Power and Energy Society General Meeting, pp.15, July 2010.

[3] Yonghua Song, Xia Yang, Zongxiang Lu, "Integration of Plug-in Hybrid and Electric Vehicles Experience from China," IEEE PES Power and Energy Society General Meeting, pp.1-6, July 2010.

[4] Thomas A. Becker, Ikhlaq Sidhu, Burghardt Tenderich, "Electric Vehicles in the United States A New Model with Forecasts to 2030," University of California, Berkeley, Center for Entrepreneurship \& Technology (CET), v.2.0, Aug. 2009.
[5] Linni Jian, Honghong Xue, Guoqing Xu, Xinyu Zhu, Dongfang Zhao, Z. Y. Shao, "Regulated Charging of Plug-in Hybrid Electric Vehicles for Minimizing Load Variance in Household Smart Microgrid," IEEE Trans. Ind. Electron., vol.60, no.8, pp.3218-3226, Aug. 2013.

[6] J. McDowall, "Conventional battery technologies-present and future," IEEE Power Engineering Society Summer Meeting, vol.3, pp. 538-1540, July 2000.

[7] Ali Emadi, Young Joo Lee, Kaushik Rajashekara, "Power Electronics and Motor Drives in Electric, Hybrid Electric, and Plug-In Hybrid Electric Vehicles," IEEE Trans. Ind. Electron., vol.55, pp.2237-2245, June 2008.

[8] Vítor Monteiro, Henrique Gonçalves, João L. Afonso, "Impact of Electric Vehicles on Power Quality in a Smart Grid Context," IEEE EPQU International Conference on Electrical Power Quality and Utilisation, pp.1-6, Oct. 2011.

[9] Murat Yilmaz, Philip T. Krein, "Review of Integrated Charging Methods for Plug-In Electric and Hybrid Vehicles," IEEE International Conference on Vehicular Electronics and Safety, pp.346-351, July 2012.

[10] Vítor Monteiro, J. G. Pinto, Bruno Exposto, João C. Ferreira, Carlos Couto, João L. Afonso, "Assessment of a Battery Charger for Electric Vehicles with Reactive Power Control," IEEE IECON Industrial Electronics Society, Montréal-Canada, pp.5124-5129, Oct. 2012.

[11] J. G. Pinto, Vítor Monteiro, Henrique Gonçalves, João L. Afonso, "Onboard Reconfigurable Battery Charger for Electric VehiclesWith Traction-to-Auxiliary Mode," IEEE Trans. Veh. Technol., vol.63, no.3, pp.1104-1116, Mar. 2014

[12] Bill Kramer, Sudipta Chakraborty, Benjamin Kroposki, "A review of plug-in vehicles and vehicle-to-grid capability," IEEE IECON Industrial Electronics Conference, pp.2278-2283, Nov. 2008.

[13] Willet Kempton, Victor Udo, Ken Huber, Kevin Komara, Steve Letendre, Scott Baker, Doug Brunner, Nat Pearre, "A test of vehicle-togrid (V2G) for energy storage and frequency regulation in the PJM system," University of Delaware, Nov. 2008.

[14] Willett Kempton, Jasna Tomic, "Vehicle-to-Grid Power Fundamentals: Calculating Capacity and net Revenue," Journal of Power Sources, vol.144, no.1, pp.268-279, Dec. 2004.

[15] Vehbi C. Gungor, Dilan Sahin, Taskin Kocak, Salih Ergut, Concettina Buccella, Carlo Cecati, Gerhard P. Hancke, "Smart Grid and Smart Homes - Key Players and Pilot Projects," IEEE Ind. Electron. Mag., vol.6, pp.18-34, Dec. 2012.

[16] Vítor Monteiro, João C. Ferreira, Andrés A. Nogueiras Meléndez, João L. Afonso, "Electric Vehicles On-Board Battery Charger for the Future Smart Grids," in Technological Innovation for the Internet of Things, 1st ed., Luis M. Camarinha-Matos, Slavisa Tomic, Paula Graça, Ed. Springer, 2013, Chapter 38, pp.351-358.

[17] A. P. Sakis Meliopoulos, George Cokkinides, Renke Huang, Evangelos Farantatos, Sungyun Choi, Yonghee Lee, Xuebei Yu, "Smart Grid Technologies for Autonomous Operation and Control," IEEE Trans. Smart Grid, vol.2, no.1, pp.1-10, Mar. 2011.

[18] João C. Ferreira, Vitor Monteiro, João L. Afonso, "Vehicle-to-Anything Application (V2Anything App) for Electric Vehicles," IEEE Trans. Ind. Informat., 2013.

[19] Marc Multin, Florian Allerding, Hartmut Schmeck, "Integration of Electric Vehicles in Smart Homes - An ICT-based Solution for V2G Scenarios," IEEE PES ISGT Innovative Smart Grid Technologies, pp.18, Jan. 2012.

[20] Green Car Congress, "Nissan to launch the 'LEAF to Home' V2H power supply system with Nichicon 'EV Power Station' in June." [Online] Available: 30-05-2012 http://www.greencarcongress.com/2012/05/leafvsh- 20120530.html.

[21] Meisam Nesary Moghadam, Hassan Taheri, "Electrical Design of 21st Century Smart Homes," IEEE Iranian Conference on Samrt Grids, pp.17, May 2012.

[22] Li Jiang, Da-you Liu, Bo Yang, "Smart Home Research," IEEE International Conference on Machine Learning and Cybernetics, vol.2, pp.659-663, Aug. 2004.

[23] J. G. Pinto, Vítor Monteiro, Henrique Gonçalves, Bruno Exposto, Delfim Pedrosa, Carlos Couto, João L. Afonso, "Bidirectional Battery Charger with Grid-to-Vehicle, Vehicle-to-Grid and Vehicle-to-Home 
Technologies," IEEE IECON Industrial Electronics Conference, pp.5934-5939, Vienna Austria, Nov. 2013.

[24] Kristien Clement-Nyns, Edwin Haesen, Johan Driesen, "The Impact of Charging Plug-In Hybrid Electric Vehicles on a Residential Distribution Grid,” IEEE Trans. Power Syst., vol.25. no.1, pp.371-380, Feb. 2010.

[25] Dirk Van Hertem, Marcel Didden, Johan Driesen, Ronnie Belmans, "Choosing the Correct Mitigation Method Against Voltage Dips and Interruptions: A Customer-Based Approach," IEEE Trans. Power Del., vol.22, no.1, pp.331-339, Jan. 2007.

[26] Masoud Karimi-Ghartemani, "Linear and Pseudolinear Enhanced Phased-Locked Loop (EPLL) Structures,” IEEE Trans. Ind. Electron., vol.61, no.3, pp.1464-1474, Mar. 2014.

[27] Antonio Moschitta, Paolo Carbone, Carlo Muscas, "Performance Comparison of Advanced Techniques for Voltage Dip Detection," IEEE Trans. Instrum. Meas., vol.61, no.5, pp.1494-1502, May 2002.

Vítor Monteiro (S'10) was born in Guimarães, Portugal, on May 1984. He received the M.Sc. in Industrial Electronics and Computers Engineering, from the School of Engineering of the University of Minho, in 2012. Since 2008 he is a member of the Group of Energy and Power Electronics (GEPE) of the Centro Algoritmi, at the University of Minho. Currently he is a $\mathrm{PhD}$ student supported by the doctoral scholarship SFRH/BD/80155/2011 granted by the Portuguese FCT agency, and a collaborator of the Centro Algoritmi of the University of Minho. His research interests are related with Power Electronics Converters, Digital Control Techniques, Smart Grids, and Electric Vehicles.

Bruno Exposto (S'10) was born in Valença, Portugal on July 28, 1982. He is a PhD student at Centro Algoritmi of University of Minho. He finished his Integrated Master Course in Industrial Electronic Engineering and Computers in the Minho University in 2010. After that he was a Research Fellow at the Department of Industrial Electronics of the University of Minho, Portugal. His researching activities are related with the Development of Voltage-source and Current Source Active Power Filters, Electrical Power Quality and Power Electronics.

J. G. Pinto (S'06) was born in Guimarães, Portugal, in 1977. He received the degree in Industrial Electronics Engineering and the M.Sc. degree in Industrial Electronics from the University of Minho, Portugal, in 2001 and 2004, respectively. From 2002 to 2006 worked as invited Assistant Lecturer at the Electrical Department of the Polytechnic Institute of Bragança, Portugal. From 2006 to 2012 he worked as a researcher at the Group of Energy and Power Electronics (GEPE) of the Centro Algoritmi, at the University of Minho. $\mathrm{He}$ received the $\mathrm{PhD}$ degree in Electronics and Computer Engineering from the University of Minho, in 2012. Since 2013 he works as invited Assistant Professor at the Industrial Electronics Department of the University of Minho. His research interests are related with Power Electronics, Power Quality and Digital Control of Power Converters.

Raul Almeida was born in Guimarães, Portugal, on October 1986. He received the M.Sc. in Industrial Electronics and Computers Engineering, from the University of Minho, in 2013. He is member of the Algoritmi Research Centre from
University of Minho, and since 2006 he integrates the Group of Energy and Power Electronics (GEPE), where he have developed his activities within the projects SINUS, UPQC-IMREI, and MOBICarPower. His research interests are related with: Power Quality, Power Electronics and instrumentation.

João C. Ferreira (M'02) was born in Angola, June 1967. $\mathrm{He}$ is Professor of Mathematics on Informatics and Telecommunication degree courses in Polytechnic Institute of Lisbon (IPL/ISEL). He is also consultant with different companies and Portuguese institutions. He graduated in Physics at Technical University of Lisbon (UTL/IST), Portugal, received an MSC in Telecommunication and a $\mathrm{PhD}$ degree in Computer Science Engineering from UTL/IST and a second $\mathrm{PhD}$ in Leaders for Technical Industries from MIT Portugal. Currently, he teaches subjects in the area of mathematics and information systems and he supervises several year end, MSc and $\mathrm{PhD}$ students. His professional and research interests are in retrieval, geographic and multimedia retrieval, Electric Vehicle, Intelligent Systems, intelligent transportation (ITS) and sustainable mobility systems. He is author or co-author of more than 130 peer-reviewed scientific papers of several international conferences and workshops in different areas of computer science.

Andrés A. Nogueiras Meléndez (M'99, S'12) was born in Rosario, Argentina, in 1967. He received the Graduate degree in industrial engineering and the Ph.D. degree (cum laude) in industrial engineering from the University of Vigo, Spain, in 1994 and 2003, respectively. He was a Research Assistant at the Applied Electronics Institute, Pedro Barrie de la Maza Foundation, Vigo, in 1994. He has been an Assistant Professor in the Electronic Technology Department, Universidad de Vigo, since 1995 and Associate Professor since 2008. His current research interests include power electronics for energy management, switched converter nonlinear modeling, applied reliability, availability, maintenance, and safety (RAMS) technologies, and teaching power electronics through the Internet. $\mathrm{He}$ is a member of the IEEE Industrial Electronics Society and the IEEE Power Electronics Society.

João Luiz Afonso (M'00) was born in Rio de Janeiro, Brazil, in 1963. He received the B.S. and M.Sc. degrees in Electrical Engineering from the Federal University of Rio de Janeiro in 1986 and 1991, respectively, and the Ph.D. degree in Industrial Electronics from the University of Minho, Guimarães, Portugal, in 2000. Since 1993, he has been with the Department of Industrial Electronics, University of Minho, where he is Associate Professor. He teaches Electrical Machines, Electrical Energy Systems, Complements of Power Electronics, Electrical Power Quality, Active Power Filters and Renewable Energy. He is a researcher with the Group of Energy and Power Electronics (GEPE), and he coordinates the thematic strand of Sustainable and Smart Cities of the Centro Algoritmi. His research interests include: Power Quality, Active Power Filters, Renewable Energy, Electric Vehicles, Energy Efficiency, Energy Storage Systems, Smart Grids and Smart Cities. 